\title{
Induction of Th1 chemokine secretion in dermal fibroblasts by vanadium pentoxide
}

\author{
P. FALLAHI ${ }^{1}$, R. FODDIS ${ }^{2}$, G. ELIA ${ }^{1}$, F. RAGUSA ${ }^{1}$, A. PATRIZIO ${ }^{1}$, G. GUGLIELMI ${ }^{3}$, G. FRENZILLI ${ }^{1}$, \\ S. BENVENGA ${ }^{4-6}$, A. CRISTAUDO ${ }^{2}$, A. ANTONELLI ${ }^{1}$ and S. M. FERRARI ${ }^{1}$
}

\begin{abstract}
Departments of ${ }^{1}$ Clinical and Experimental Medicine and ${ }^{2}$ Translational Research and New Technologies in Medicine and Surgery, University of Pisa, I-56126 Pisa; ${ }^{3}$ U.O. Medicina Preventiva del Lavoro, Azienda Ospedaliero-Universitaria Pisana, I-56124 Pisa; ${ }^{4}$ Department of Clinical and Experimental Medicine; ${ }^{5}$ Master Program on Childhood, Adolescent and Women's Endocrine Health, University of Messina; ${ }^{6}$ Interdepartmental Program of Molecular and Clinical Endocrinology and Women's Endocrine Health,
\end{abstract} Azienda Ospedaliera Universitaria Policlinico ‘G. Martino', I-98125 Messina, Italy

Received November 1, 2017; Accepted February 22, 2018

DOI: $10.3892 / \mathrm{mmr} .2018 .8712$

\begin{abstract}
Vanadium is a soft, silvery-grey metal with a number of different oxidation states. The most common commercial form of vanadium is vanadium pentoxide $\left(\mathrm{V}_{2} \mathrm{O}_{5}\right)$. All vanadium compounds are considered toxic. An increase in skin rashes has been observed in certain vanadium workers, including the development of atopic dermatitis. However, to the best of our knowledge, no prior in vivo or in vitro studies have evaluated the effect of vanadium exposure in human dermal fibroblasts. The present study evaluated the effect of $\mathrm{V}_{2} \mathrm{O}_{5}$ on proliferation and chemokine secretion in dermal fibroblasts. The results revealed that $\mathrm{V}_{2} \mathrm{O}_{5}$ had no significant effect on the viability or proliferation of fibroblasts, however it was able to induce the secretion of T-helper (Th) 1 chemokines from dermal fibroblasts, synergistically increasing the effect of important Th1 cytokines, including interferon- $\gamma$ and tumor necrosis factor- $\alpha$. Through these processes, $\mathrm{V}_{2} \mathrm{O}_{5}$ may lead to the induction and perpetuation of an inflammatory reaction in dermal tissue. The induction and perpetuation of inflammation in the dermis and the variety of involved candidate genes may be at the base of $\mathrm{V}_{2} \mathrm{O}_{5}$-induced effects following occupational and environmental exposures. Further studies are necessary to evaluate dermal integrity and manifestations in subjects who are occupationally exposed, or living in polluted areas.
\end{abstract}

Correspondence to: Professor A. Antonelli, Department of Clinical and Experimental Medicine, University of Pisa, Via Savi 10, I-56126 Pisa, Italy

E-mail: alessandro.antonelli@med.unipi.it

Key words: vanadium, chemokine (C-X-C motif) ligand 10, chemokine (C-X-C motif) ligand 9, chemokines, dermal fibroblasts, environmental exposure, occupational exposure

\section{Introduction}

Vanadium is a soft, silvery-grey metal, which exists in a number of different oxidation states $(-1,0,+2,+3,+4$ and +5$)$; vanadium pentoxide $\left(\mathrm{V}_{2} \mathrm{O}_{5}\right)$ is the most common commercial form, and most of the studies on toxicity have been conducted on vanadium pentoxide, as it is the primary form found in industrial exposure situations (1). All vanadium compounds are considered toxic. The Occupational Safety and Health Administration (Bellevue, WA, USA) have set an exposure limit for the workplace (considering an $8 \mathrm{~h}$ workday, and a $40 \mathrm{~h}$ work week), of $0.05 \mathrm{mg} / \mathrm{m}^{3}$ for $\mathrm{V}_{2} \mathrm{O}_{5}$ dust and $0.1 \mathrm{mg} / \mathrm{m}^{3}$ for $\mathrm{V}_{2} \mathrm{O}_{5}$ fumes (2).

The exposure dose of vanadium that is considered lifethreatening is $35 \mathrm{mg} / \mathrm{m}^{3}$ [as determined by the National Institute for Occupational Safety and Health (NIOSH; Washington, DC, USA)], which could cause serious and perpetuating health issues, including death (2). The respiratory system is the most vulnerable to vanadium toxicity, while the effect on the gastrointestinal system is minimal due to the low gut absorption rate (3-5). However, quantitative data are not sufficient to obtain a chronic or subchronic inhalation reference dose.

In rat models, the effects resulting from an inhaled or oral vanadium were evaluated in the sera $(6,7)$, nervous tissue $(8)$, liver (9) and other types of tissue (kidney, gut, lungs) development (10). In vanadium workers (NIOSH 1983) increases in skin rashes and atopic dermatitis have been recorded. To the best of our knowledge, no prior in vivo or in vitro studies have been conducted to evaluate the effect of vanadium exposure on dermal fibroblasts. Here, we evaluated the effect of $\mathrm{V}_{2} \mathrm{O}_{5}$ on the proliferation and chemokine secretion profiles of dermal fibroblasts.

\section{Materials and methods}

Fibroblast cell cultures. Dermal fibroblasts were obtained from 6 patients who underwent surgery for thyroid nodular goiter (discarded dermal material was used). The local Ethics Committee of the University of Pisa approved the study protocol, and all subjects provided informed consent. 
As previously described, tissue explants from the derma were minced and placed in culture dishes, to allow the fibroblasts to proliferate (11). Fibroblasts were propagated in Medium 199 containing 20\% FBS (Gibco; Invitrogen, Ltd., Paisley, UK), gentamycin $(20 \mu \mathrm{g} / \mathrm{ml})$ and penicillin $(100 \mathrm{U} / \mathrm{ml})$, in a $37^{\circ} \mathrm{C}$ humidified incubator with $5 \%$ of $\mathrm{CO}_{2}$. Cells were subsequently maintained in medium 199 containing $10 \%$ FBS (and antibiotics) (12).

Cell viability and proliferation assay. The evaluation of cell proliferation and viability was conducted using a WST-1 assay (Roche Diagnostics, Almere, The Netherlands), which uses MTT $(13,14)$. Fibroblasts were seeded $(35,000$ cells $/ \mathrm{ml}$, in a final volume of $100 \mu \mathrm{l}$ ) into 96 -well plates. The effect $\mathrm{V}_{2} \mathrm{O}_{5}$ on fibroblast proliferation was determined following exposure of the cells for $24 \mathrm{~h}$ to increasing concentrations of $\mathrm{V}_{2} \mathrm{O}_{5}$ (1, 10 and $100 \mathrm{nM})$. Cells were then plated and treated for $24 \mathrm{~h}$ with $\mathrm{V}_{2} \mathrm{O}_{5}$, or with its vehicle alone; all experiments were performed in triplicate for each cell preparation.

Proliferation assay: cell counting. The cell counting assay was also used to assess fibroblast proliferation $(13,14)$.

Chemokines secretion assays. Chemokine (C-X-C motif) ligand (CXCL) 9 and CXCL10 secretion assays were performed by seeding 30,000 cells/ml into 96 -well plates, with a final volume of $100 \mu \mathrm{l} /$ well, in growth medium that was removed after $24 \mathrm{~h}$. Cells were subsequently washed in PBS, then incubated $(24 \mathrm{~h})$ in phenol red and serum-free medium with interferon (IFN) $-\gamma$ (R\&D Systems, Minneapolis, MN, USA; $500 ; 1,000 ; 5,000 ; 10,000 \mathrm{IU} / \mathrm{ml})$, and/or $10 \mathrm{ng} / \mathrm{ml}$ tumor necrosis factor (TNF)- $\alpha$ (R\&D Systems) (11). Preliminary experiments were conducted to select the TNF- $\alpha$ concentration, in order to obtain the highest secretion rate. The supernatants were collected after $24 \mathrm{~h}$, then frozen at $-20^{\circ} \mathrm{C}$ until use in the chemokine assay.

To understand the effect of $\mathrm{V}_{2} \mathrm{O}_{5}$ on the chemokine secretion induced by IFN- $\gamma$, cells were treated for $24 \mathrm{~h}$ with increasing concentrations of $\mathrm{V}_{2} \mathrm{O}_{5}(1,10$ and $100 \mathrm{nM})$, in the presence or absence of IFN- $\gamma(1,000 \mathrm{IU} / \mathrm{ml})$, and/or TNF- $\alpha(10 \mathrm{ng} / \mathrm{ml})$. An ELISA was used to measure the CXCL9 and CXCL10 levels in the supernatants. The experiments were performed three times for each different cell preparation.

ELISA for CXCL9 and CXCL10. CXCL9 and CXCL10 were assessed in the supernatants obtained from cell cultures, using commercially available kits (R\&D Systems). The minimum (mean) detectable doses were 1.5 and $1.2 \mathrm{pg} / \mathrm{ml}$ for CXCL9 and CXCL10, respectively. The intra- and inter-assay coefficients of variation were 3.5 and $6.4 \%$ respectively, for CXCL9, and 4.5 and $7.3 \%$ respectively, for CXCL10. Quality control pools of normal, low and high concentrations were also included in each assay.

Data analysis. For normally distributed variables, values are given as the mean $\pm \mathrm{SD}$ in text, and in figures, otherwise as the median and interquartile range. Mean group values were compared using one-way analysis of variance (ANOVA) for variables normally distributed variables, or by using the Kruskal-Wallis test or Mann-Whitney U test. Proportions were compared using the Chi-square test. In addition, the

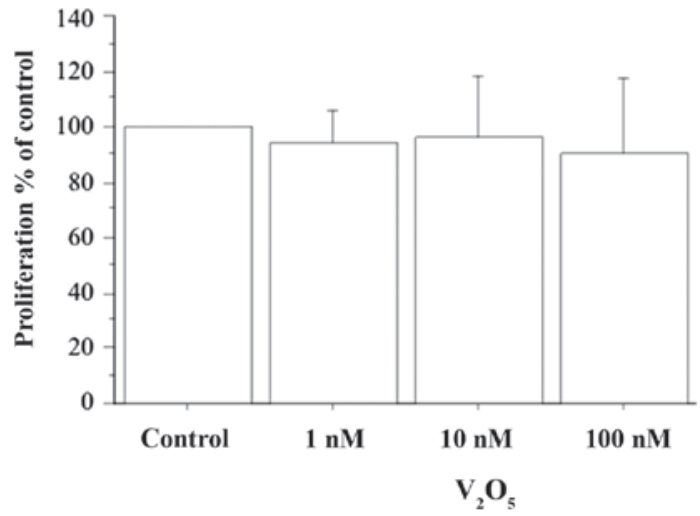

Figure 1 . The WST-1 cell viability and proliferation assay showed that $\mathrm{V}_{2} \mathrm{O}_{5}$ (1, 10 and $100 \mathrm{nM})$ does not alter the viability or proliferation of dermal fibroblasts (mean group values were compared using one-way analysis of variance; the Bonferroni-Dunn test was used for post hoc comparisons; $\mathrm{P}>0.05$ for all comparisons). $\mathrm{V}_{2} \mathrm{O}_{5}$, vanadium pentoxide.

Bonferroni-Dunn test was used for the post hoc comparison of normally distributed variables.

\section{Results}

Cell proliferation. The WST-1 cell viability and proliferation assay showed that $\mathrm{V}_{2} \mathrm{O}_{5}(1,10$ and $100 \mathrm{nM})$ did not alter the viability or proliferation of dermal fibroblasts (Fig. 1). These results were confirmed by a cell counting assay (data not presented).

CXCL9. CXCL9 was not detectable in the supernatants gathered from primary fibroblast samples, whereas its concentration was elevated following IFN- $\gamma$ dose-dependent induction $(0,75 \pm 31,141 \pm 29,210 \pm 35$ and $297 \pm 74 \mathrm{pg} / \mathrm{ml}$ for IFN- $\gamma$ 0; 500; 1,000; 5,000 and 10,000 IU/ml, respectively; $\mathrm{P}<0.001$, ANOVA). TNF- $\alpha$ alone had no significant impact on CXCL9, which remained undetectable, whereas IFN- $\gamma$ plus TNF- $\alpha$ exhibited a synergistic effect on the CXCL9 release (CXCL9, 11,154 $\pm 1,673$ vs. $151 \pm 42 \mathrm{pg} / \mathrm{ml}$ with IFN- $\gamma$ alone; $\mathrm{P}<0.0001$, ANOVA)

CXCL9 release was dose-dependently stimulated $(\mathrm{P}<0.0001, \mathrm{ANOVA})$ when fibroblasts were treated with increasing $\mathrm{V}_{2} \mathrm{O}_{5}$ concentrations (1, 10 and $100 \mathrm{nM}$ ) (Fig. 2A). Following the treatment of fibroblasts with $\mathrm{V}_{2} \mathrm{O}_{5}(1,10$ and $100 \mathrm{nM}$ ), together with TNF- $\alpha$, CXCL9 secretion was not significantly changed with respect to $\mathrm{V}_{2} \mathrm{O}_{5}$ alone (data not presented). Treating fibroblasts with $100 \mathrm{nM} \mathrm{V} \mathrm{O}_{5}$ plus IFN- $\gamma$ induced a synergistic increase in CXCL9 release $(\mathrm{P}<0.0001$, ANOVA) (Fig. 3A). When fibroblasts were treated with $\mathrm{V}_{2} \mathrm{O}_{5}$ $(100 \mathrm{nM})$, together with IFN- $\gamma$ and TNF- $\alpha$ stimulation, CXCL9 release was synergistically increased $(\mathrm{P}<0.0001$, ANOVA) (Fig. 4A).

CXCL10. CXCL10 was also not detectable in the supernatants obtained from primary fibroblast cultures under basal conditions. IFN- $\gamma$ induced CXCL10 secretion dose-dependently $(0,34 \pm 18,107 \pm 42,187 \pm 32$ and $272 \pm 76 \mathrm{pg} / \mathrm{ml}$, respectively, for IFN- $\gamma$ 0; 500; 1,000; 5,000; 10,000 IU/ml; ANOVA, P<0.001). TNF- $\alpha$ alone did not have a significant impact on CXCL10 secretion, whereas IFN- $\gamma$ plus TNF- $\alpha$ exhibited a synergistic 

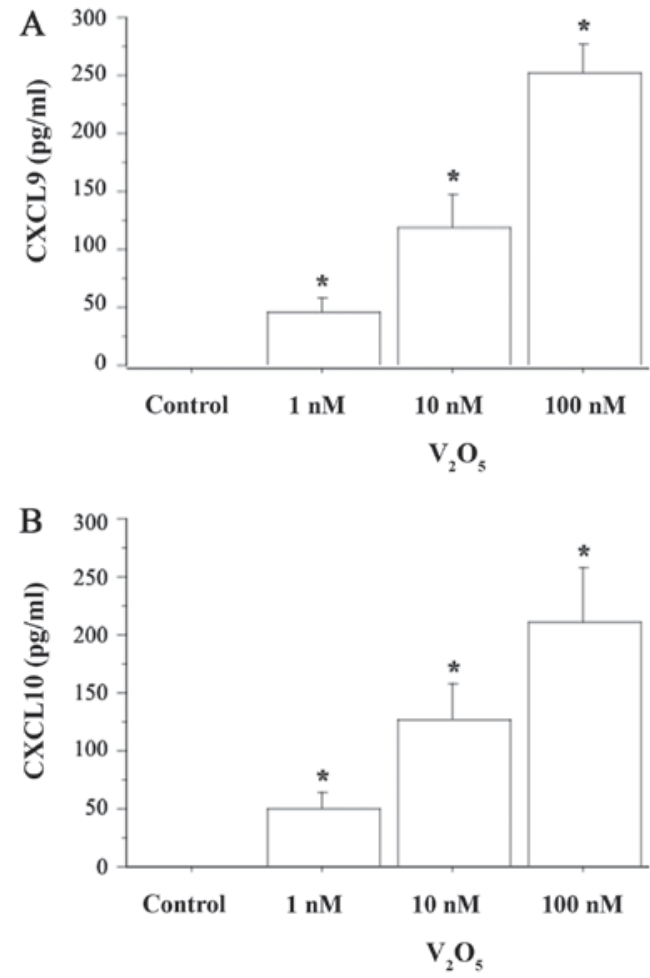

Figure 2. Following the treatment of dermal fibroblasts with $\mathrm{V}_{2} \mathrm{O}_{5}(1,10$ and $100 \mathrm{nM}$ ), (A) CXCL9 and (B) CXCL10 secretion was dose-dependently stimulated $(\mathrm{P}<0.0001$ by one-way analysis of variance). Bonferroni-Dunn test was used for post hoc comparisons. ${ }^{*} \mathrm{P}<0.05$ vs. the control. $\mathrm{V}_{2} \mathrm{O}_{5}$, vanadium pentoxide; $\mathrm{CXCL}$, chemokine (C-X-C motif) ligand.

effect on CXCL10 secretion $(3,043 \pm 234$ vs. $117 \pm 27 \mathrm{pg} / \mathrm{ml}$ with IFN $-\gamma$ alone; $\mathrm{P}<0.0001$, ANOVA).

CXCL10 release was dose-dependently stimulated $(\mathrm{P}<0.0001, \mathrm{ANOVA})$ when fibroblasts were treated with increasing $\mathrm{V}_{2} \mathrm{O}_{5}$ concentrations $(1,10$ and $100 \mathrm{nM}$ ) (Fig. 2B). Following the treatment of fibroblasts with $\mathrm{V}_{2} \mathrm{O}_{5}(1,10$ and $100 \mathrm{nM}$ ), and together with TNF- $\alpha$, CXCL10 secretion was not significantly changed with respect to $\mathrm{V}_{2} \mathrm{O}_{5}$ alone (data not presented).

Treating fibroblasts with $100 \mathrm{nM} \mathrm{V} \mathrm{V}_{2} \mathrm{O}_{5}$ plus IFN- $\gamma$ caused a synergistic increase in CXCL10 release $(\mathrm{P}<0.0001$, ANOVA) (Fig. 3B). When fibroblasts were treated with $\mathrm{V}_{2} \mathrm{O}_{5}(100 \mathrm{nM})$ together with IFN- $\gamma$ and TNF- $\alpha$ stimulation, CXCL10 release was also synergistically increased $(\mathrm{P}<0.0001$, ANOVA) (Fig. 4B).

\section{Discussion}

The results of the present study demonstrated that $\mathrm{V}_{2} \mathrm{O}_{5}$ could promote IFN- $\gamma$-dependent chemokine secretion in dermal fibroblasts, without altering their cell proliferation and viability. In addition, our results confirmed that IFN- $\gamma$ and TNF- $\alpha$ stimulate CXCL9 and CXCL10 secretion, as hypothesized $(11,15)$. It is notable that $\mathrm{V}_{2} \mathrm{O}_{5}$ was able to synergize with IFN $-\gamma$ and TNF- $\alpha$, further increasing chemokines secretion.

These results are concordant with the hypothesis that $\mathrm{V}_{2} \mathrm{O}_{5}$ is able to induce and perpetuate inflammation in the dermal tissues, evolving from a predominant T-helper (Th)1 immune response (13). IFN- $\gamma$-inducible C-X-C chemokines are secreted by several types of mammalian cells, including fibroblasts,
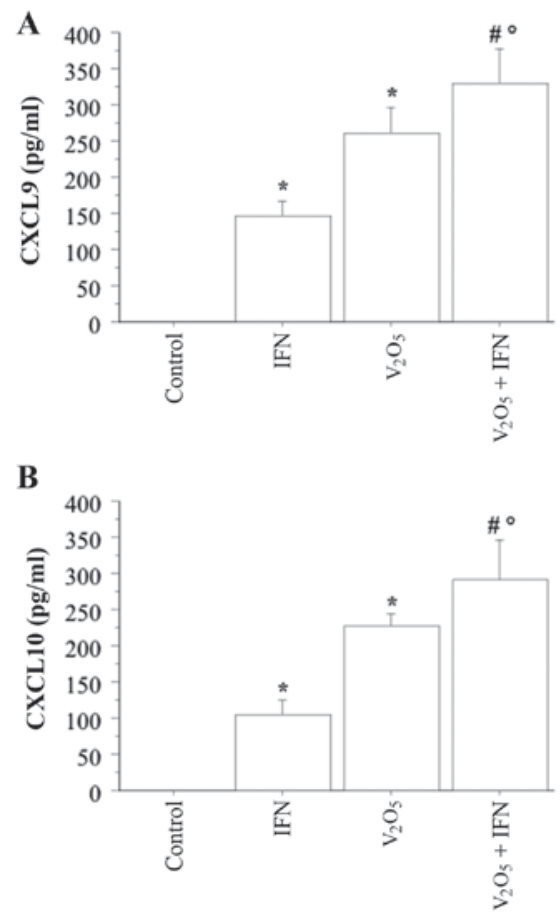

Figure 3. Treating dermal fibroblasts with $\mathrm{V}_{2} \mathrm{O}_{5}(100 \mathrm{nM})$, together with IFN- $\gamma$, synergistically increased (A) CXCL9 and (B) CXCL10 release ( $\mathrm{P}<0.0001$ by one-way analysis of variance). Bonferroni-Dunn test was used for post hoc comparisons. " $\mathrm{P}<0.05$ vs. the control; ${ }^{\prime} \mathrm{P}<0.05$ vs. IFN; ${ }^{\circ} \mathrm{P}<0.05$ vs. $\mathrm{V}_{2} \mathrm{O}_{5} . \mathrm{V}_{2} \mathrm{O}_{5}$, vanadium pentoxide; $\mathrm{CXCL}$, chemokine (C-X-C motif) ligand; IFN, interferon.
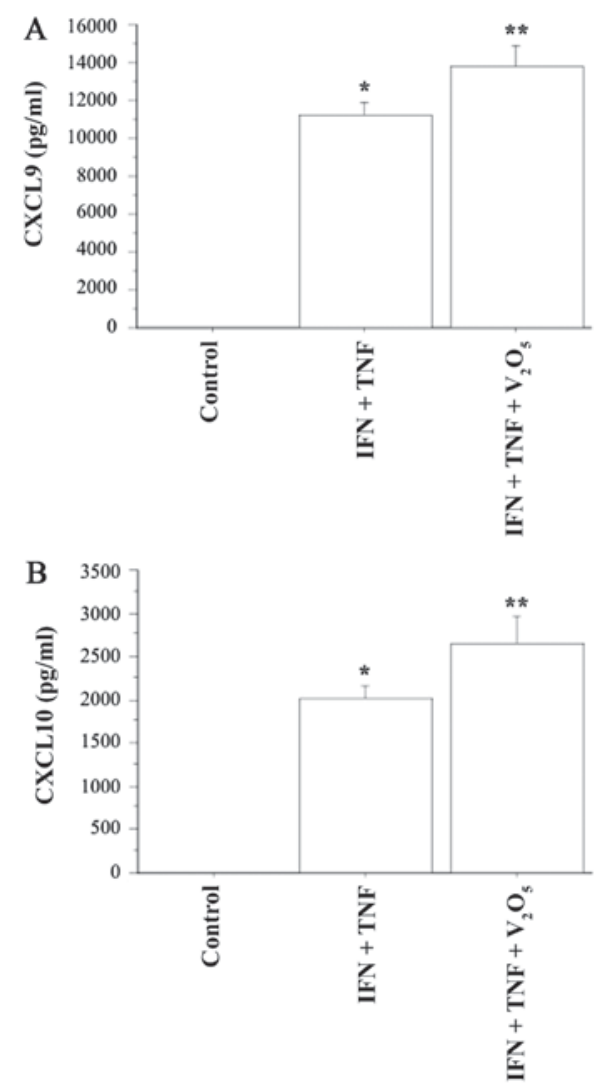

Figure 4. Treating dermal fibroblasts with $\mathrm{V}_{2} \mathrm{O}_{5}(100 \mathrm{nM})$, together with IFN- $\gamma$ plus TNF- $\alpha$, synergistically increased (A) CXCL9 and (B) CXCL10 secretion $(\mathrm{P}<0.0001$ by one-way analysis of variance). Bonferroni-Dunn test was used for post hoc comparisons. ${ }^{*} \mathrm{P}<0.05$ vs. the control; ${ }^{* *} \mathrm{P}<0.05$ vs. IFN+TNF. $\mathrm{V}_{2} \mathrm{O}_{5}$, vanadium pentoxide; CXCL, chemokine (C-X-C motif) ligand; IFN, interferon; TNF, tumor necrosis factor. 
thyrocytes, islet cells, colon epithelial cells and endothelial cells, among others (11,13-21). These cell types are unable to produce these chemokines under basal conditions; they are induced following stimulation by IFN- $\gamma$ (alone or in combination with TNF- $\alpha$ ), a cytokine that is produced by Th1-activated lymphocytes in several autoimmune diseases, including in the thyroid in Graves' disease, and in autoimmune thyroiditis. It has been hypothesized that this process can be involved in the initiation and/or the perpetuation of various autoimmune disorders $(11,13-21)$, and that it may also be applied to the thyroid.

Our results are concordant with those of other studies in different cell types. $\mathrm{V}_{2} \mathrm{O}_{5}$ exposure is a cause of occupational bronchitis; an in vitro study was conducted to evaluate the gene expression profiles of human lung fibroblasts following $\mathrm{V}_{2} \mathrm{O}_{5}$ exposure, in order to identify genes that might play a role in the bronchial inflammation, repair and fibrosis during the pathogenesis of bronchitis. A dozen genes are overexpressed by $\mathrm{V}_{2} \mathrm{O}_{5}$, including CXCL9 and CXCL1O (1). A further study reported that fibroblasts responded to vanadium oxidative stress by producing IFN- $\beta$ and activating STAT-1, which lead to increased CXCL10 levels (22), thus serving a role in the innate immune response.

It is notable that vanadium is able to increase chemokine secretion in the dose range of 1-100 nM. Since the normal blood levels of vanadium range from 0.45-18.4 nM, $100 \mathrm{nM}$ could be noted as a dose that might mimic an abnormally high exposure (23). Thus, we could hypothesize that $\mathrm{V}_{2} \mathrm{O}_{5}$ in this concentration range is able to induce an inflammatory reaction in dermal tissues, prompting the appearance of skin rashes or atopic dermatitis.

Moreover, it has been shown that exposure of human skin fibroblasts to vanadate causes DNA strand breaks at relevant concentration of $1 \mu \mathrm{M}$ (24). In the present study we have considered lower concentrations (1, 10 and $100 \mathrm{nM})$, that did not alter the viability or proliferation of dermal fibroblasts.

In conclusion, the results of our study showed that $\mathrm{V}_{2} \mathrm{O}_{5}$ is able to induce Th1 chemokine secretion in dermal tissues, and that it can synergize with important Th1 cytokines (such as IFN- $\gamma$ and TNF- $\alpha$ ), leading to the induction and perpetuation of inflammation in the dermis. Moreover, different genes are overexpressed by $\mathrm{V}_{2} \mathrm{O}_{5}$, including CXCL9 and CXCL10, that appear to have important functions in inflammation, fibrosis and repair. To the best of our knowledge, no prior study has evaluated the immune modulatory effects of vanadium in dermal fibroblasts; therefore, our results could be important for evaluating the pathogenesis of clinical dermatological manifestations of vanadium exposure in humans. The induction and perpetuation of inflammation in the dermis and the variety of involved candidate genes could be at the basis of $\mathrm{V}_{2} \mathrm{O}_{5}$-induced effects after occupational and environmental exposures. Additional studies are required to assess dermal integrity, as well as the manifestations of toxicity in subjects who are occupationally exposed, or are living in polluted areas.

\section{Acknowledgements}

Not applicable.

\section{Funding}

No funding was received.

\section{Availability of data and materials}

All data generated or analyzed during this study are included in this published article.

\section{Authors' contributions}

PF, RF, AC, AA and SMF made substantial contributions to the conception and design of the study and to the acquisition of the data. GE, FR, AP, GG, GF and SB analysed the data. PF, AA and SMF. have been involved in drafting the manuscript. AA critically revised the manuscript for important intellectual content.

\section{Ethics approval and consent to participate}

Not applicable.

\section{Consent for publication}

Not applicable.

\section{Competing interests}

The authors confirm that they have no competing interests.

\section{References}

1. Ingram JL, Antao-Menezes A, Turpin EA, Wallace DG, Mangum JB, Pluta LJ, Thomas RS and Bonner JC: Genomic analysis of human lung fibroblasts exposed to vanadium pentoxide to identify candidate genes for occupational bronchitis. Respir Res 8: 34, 2007.

2. Occupational Safety and Health Administration (OSHA): Occupational safety and health guideline for vanadium pentoxide dust. OSHA, Washington, DC, 2007.

3. Sax NI: Dangerous Properties of Industrial Materials. 6th edition. Van Nostrand Reinhold Company, New York, NY, pp2717-2720, 1984.

4. Ress NB, Chou BJ, Renne RA, Dill JA, Miller RA, Roycroft JH, Hailey JR, Haseman JK and Bucher JR: Carcinogenicity of inhaled vanadium pentoxide in $\mathrm{F} 344 / \mathrm{N}$ rats and $\mathrm{B} 6 \mathrm{C} 3 \mathrm{~F} 1$ mice. Toxicol Sci 74: 287-296, 2003.

5. Wörle-Knirsch JM, Kern K, Schleh C, Adelhelm C, Feldmann C and Krug HF: Nanoparticulate vanadium oxide potentiated vanadium toxicity in human lung cells. Environ Sci Technol 41: 331-336, 2007.

6. Scibior A, Zaporowska H and Ostrowski J: Selected haematological and biochemical parameters of blood in rats after subchronic administration of vanadium and/or magnesium in drinking water. Arch Environ Contam Toxicol 51: 287-295, 2006.

7. González-Villalva A,Fortoul T, Avila-Costa MR, Piñón-Zarate G, Rodriguez-Laraa V, Martínez-Levy G, Rojas-Lemus M, BizarroNevarezP,Díaz-BechP,Mussali-GalanteP and Colin-BarenqueL: Thrombocytosis induced in mice after subacute and subchronic $\mathrm{V}_{2} \mathrm{O}_{5}$ inhalation. Toxicol Ind Health 22: 113-116, 2006.

8. Soazo M and Garcia GB: Vanadium exposure through lactation produces behavioral alterations and CNS myelin deficit in neonatal rats. Neurotoxicol Teratol 29: 503-510, 2007.

9. Kobayashi K, Himeno S, Satoh M, Kuroda J, Shibata N, Seko Y and Hasegawa T: Pentavalent vanadium induces hepatic metallothionein through interleukin-6-dependent and -independent mechanisms. Toxicology 228: 162-170, 2006.

10. Barceloux DG: Vanadium. J Toxicol Clin Toxicol 37: 265-278, 1999.

11. Antonelli A, Ferri C, Fallahi P, Ferrari SM, Frascerra S, Sebastiani M, Franzoni F, Galetta F and Ferrannini E: High values of CXCL10 serum levels in patients with hepatitis C associated mixed cryoglobulinemia in presence or absence of autoimmune thyroiditis. Cytokine 42: 137-143, 2008. 
12. Valyasevi RW, Harteneck DA, Dutton CM and Bahn RS Stimulation of adipogenesis, peroxisome proliferator-activated receptor-gamma (PPARgamma), and thyrotropin receptor by PPARgamma agonist in human orbital preadipocyte fibroblasts. J Clin Endocrinol Metab 87: 2352-2358, 2002.

13. Antonelli A, Rotondi M, Fallahi P, Romagnani P, Ferrari SM, Buonamano A, Ferrannini E and Serio M: High levels of circulating CXC chemokine ligand 10 are associated with chronic autoimmune thyroiditis and hypothyroidism. J Clin Endocrinol Metab 89: 5496-5499, 2004.

14. Kemp EH, Metcalfe RA, Smith KA, Woodroofe MN, Watson PF and Weetman AP: Detection and localization of chemokine gene expression in autoimmune thyroid disease. Clin Endocrinol (Oxf) 59: 207-213, 2003.

15. Antonelli A, Ferrari SM, Fallahi P, Frascerra S, Santini E, Franceschini SS and Ferrannini E: Monokine induced by interferon gamma (IFNgamma) (CXCL9) and IFNgamma inducible T-cell alpha-chemoattractant (CXCL11) involvement in Graves' disease and ophthalmopathy: Modulation by peroxisome proliferator-activated receptor-gamma agonists. J Clin Endocrinol Metab 94: 1803-1809, 2009.

16. Antonelli A, Ferrari SM, Frascerra S, Pupilli C, Mancusi C, Metelli MR, Orlando C, Ferrannini E and Fallahi P: CXCL9 and CXCL11 chemokines modulation by peroxisome proliferator-activated receptor-alpha agonists secretion in Graves' and normal thyrocytes. J Clin Endocrinol Metab 95: E413-E420, 2010.

17. Garcià-Lòpez MA, Sancho D, Sànchez-Madrid F and Marazuela M: Thyrocytes from autoimmune thyroid disorders produce the chemokines IP-10 and Mig and attract CXCR3 lymphocytes. J Clin Endocrinol Metab 86: 5008-5016, 2001.
18. Antonelli A, Ferrari SM, Corrado A, Ferrannini E and Fallahi P: CXCR3, CXCL10 and type 1 diabetes. Cytokine Growth Factor Rev 25: 57-65, 2014

19. Antonelli A, Ferrari SM, Giuggioli D, Ferrannini E, Ferri C and Fallahi P: Chemokine (C-X-C motif) ligand (CXCL) 10 in autoimmune diseases. Autoimmun Rev 13: 272-280, 2014.

20. Antonelli A, Fallahi P, Delle Sedie A, Ferrari SM, Maccheroni M, Bombardieri S, Riente L and Ferrannini E: High values of Th1 (CXCL10) and Th2 (CCL2) chemokines in patients with psoriatic arthtritis. Clin Exp Rheumatol 27: 22-27, 2009.

21. Fallahi P, Ferrari SM, Ruffilli I, Elia G, Biricotti M, Vita R, Benvenga $S$ and Antonelli A: The association of other autoimmune diseases in patients with autoimmune thyroiditis: Review of the literature and report of a large series of patients. Autoimmun Rev 15: 1125-1128, 2016.

22. Antao-Menezes A, Turpin EA, Bost PC, Ryman-Rasmussen JP and Bonner JC: STAT-1 signaling in human lung fibroblasts is induced by vanadium pentoxide through an IFN-beta autocrine loop. J Immunol 180: 4200-4207, 2008.

23. Sabbioni E, Kuèera J, Pietra R and Vesterberg O: A critical review on normal concentrations of vanadium in human blood, serum, and urine. Sci Total Environ 188: 49-58, 1996.

24. Ivancsits S, Pilger A, Diem E, Schaffer A and Rüdiger HW: Vanadate induces DNA strand breaks in cultured human fibroblasts at doses relevant to occupational exposure. Mutat Res 519: 25-35, 2002. 